\title{
Edge influence on plant litter biomass in forest and savanna in the Brazilian cerrado
}

\author{
PAVEL DODONOV ${ }^{1,2 \star}$ ANDREZA L. BRAGA, ${ }^{1}$ KAREN A. HARPER $^{3}$ AND \\ DALVA M. SILVA MATOS ${ }^{1}$ \\ ${ }^{1}$ Ecology and Conservation Lab, Department of Hydrobiology, Federal University of São Carlos, São \\ Carlos, SP, (E-mail: pdodonov@gmail.com), 22Applied Ecology and Conservation Lab, Department of \\ Biological Science, State University of Santa Cruz, Rodovia Ilhéus-Itabuna, km 16, Ilhéus, BA, \\ 45662-000, Brazil, and ${ }^{3}$ School for Resource and Environmental Studies, Faculty of Management, \\ Dalhousie University, Halifax, Nova Scotia, Canada
}

\begin{abstract}
Edge influence, characterized by differences in ecosystem characteristics between the edge and the interior of remnants in fragmented landscapes, affects a variety of organisms and ecosystem processes. An important feature that may be affected by edges is the amount of plant litter, which provides important habitat for a large variety of organisms and influences ecological processes such as fire dynamics. We studied edge influence on plant litter and fine woody debris in the cerrado of São Paulo state, south-eastern Brazil. We collected, sorted, dried and weighed plant litter along $180 \mathrm{~m}$-long transects perpendicular to three savanna and eleven forest edges adjacent to different anthropogenic land uses, with four to five transect per edge. There tended to be less biomass of the finer portions of fine woody debris at both savanna and forest edges. Graminoid litter at savanna edges was greater than in the corresponding interior areas, whereas other litter portions were either unaffected by edges or did not show consistent patterns in either savanna or forest. Edge influence was usually restricted to the first $20 \mathrm{~m}$ from the edge, was not influenced by edge characteristics and exhibited no clear differences between savanna and forest areas. Several mechanisms may have led to the variable patterns observed including variation in the plant community, plant architecture, and invasive species. The edge-related variation in plant litter may putatively lead to, for example, increased fire frequency and intensity at the savanna edges and altered trophic dynamics at forest edges; the mechanisms and consequences of this edge influence should be addressed in future studies.
\end{abstract}

Key words: cerrado, edge effects, edge influence, fine woody debris, grasses.

\section{INTRODUCTION}

Edge influence has a major impact in fragmented landscapes, where a once continuous native ecosystem is replaced by a mosaic of habitat patches of different sizes surrounded by an anthropogenic matrix (Fahrig 2003). Edge influence comprises modifications that occur at the edge of vegetation fragments as a result of the influence of the adjacent matrix and may result in profound modifications to the structure, composition and functioning of an ecosystem close to the edge when compared to the interior (Harper et al. 2005). In addition to the commonly observed changes in microclimate at the forest edge (e.g. Didham \& Lawton 1999; Pohlman et al. 2007), edges may affect vegetation structure and composition (Delgado et al. 2007; Magrach et al. 2014), soil characteristics (Bettez et al. 2013), ecological processes such as decomposition and primary

${ }^{\star}$ Corresponding author.

Accepted for publication July 2016.

C 2016 Ecological Society of Australia productivity (Didham 1998; Bowering et al. 2006), and plant-animal interactions (Valladares et al. 2006; Huang et al. 2009). These effects are not restricted to forest environments, as they have also been observed in savannas and grasslands in different continents (Cilliers et al. 2008; Dodonov et al. 2013). Specifically for savannas, edge influence has been observed for vegetation structure and composition (Lima-Ribeiro 2008; Smit \& Asner 2012), distributions of native and exotic grass species (Pivello et al. 1999a,b), plants with different dispersal syndromes (Jardim \& Batalha 2009), and interactions between plants and invertebrates (Christianini \& Oliveira 2013). However, some ecosystem properties and processes, including those related to plant litter, have been little studied at edges despite their ecological importance (but see Didham \& Lawton 1999; Delgado et al. 2013a,b).

Plant litter, that is fallen leaves and fine woody material (Sayer 2006), is important habitat for many invertebrates (Delgado et al. 2013a,b) and a critical type of fuel (Hoffmann et al. 2012). Litter results 
from the balance of the ecological processes of senescence and decomposition, and may influence regenerating plant communities (Loydi et al. 2014). Thus, edge-related variation in plant litter may be influenced by and result in cascading effects (Harper et al. 2005) on various ecological patterns and processes. Edge-related patterns in the biomass or depth of plant litter have been observed in different ecosystems, including the Amazonian rainforest (Didham \& Lawton 1999), subtropical forests in the Canary Islands (Delgado et al. 2013a), European temperate forests (Taboada et al. 2004) and North American forests (Matlack 1993; Haskell 2000). Such patterns, however, are not consistent, as some studies report significant edge influence on plant litter at some sites but not at others (Didham \& Lawton 1999). Whereas some studies observed a greater quantity of plant litter at the edge (Didham \& Lawton 1999), others found more plant litter in the forest interior (Matlack 1993; Haskell 2000; Taboada et al. 2004; Delgado et al. 2013a).

The large variation in the observed patterns may be due in part to the combination of processes determining the amount of plant litter. In addition to variation in species composition (Didham \& Lawton 1999), the amount of plant litter is determined mainly by primary productivity, leaf loss and litter decomposition; therefore changes in litter biomass may be considered part of a secondary stage of edge influence (c.f. secondary response, Harper et al. 2005). Increases in primary productivity have been observed at some edges and were related to a greater light incidence (Bowering et al. 2006) or water availability (Smit \& Asner 2012). Increases in wind speed leading to a greater leaf loss are also a common pattern at forest edges (Laurance \& Curran 2008). Accordingly, increased litter production at edges has been observed in the Amazonian rainforest (Vasconcelos \& Luizão 2004) and in an atlantic forest fragment in Brazil (Portela \& Santos 2007). However, opposite patterns, with decreased litterfall at forest edges, were observed in a different Brazilian atlantic forest area (Vidal et al. 2007) and in the Canary Islands (Arévalo et al. 2008). Temporal variation in litterfall patterns have also been observed, with litterfall being greater at the edge than in the interior only in the first year after edge creation (Sizer et al. 2000). Similar variation in edge influence has been also reported for litter decomposition rates, with decomposition at the edge being either greater (Didham 1998), smaller (Riutta et al. 2012) or equal to that in the reference conditions (Rubinstein \& Vasconcelos 2005; Moreno et al. 2014).

Patterns of edge influence on microclimate, vegetation structure and other variables often differ among vegetation types (Delgado et al. 2007; Dodonov et al. 2013; but see Delgado et al. 2013a). Specifically for plant litter, different patterns may be expected for forest and savanna environments, which have markedly different ground layer structure (Hoffmann et al. 2012) and are likely to face different mechanisms of edge influence. For example edge influence in savanna environments may be caused by factors such as altered hydrological regime leading to increases in woody plant cover (Smit \& Asner 2012) and increased abundance of invasive grasses (Pivello et al. 1999a,b; Dodonov et al. 2013; Mendonça et al. 2015). This may result in varying patterns of edge influence. Whereas increases in woody plant cover may lead to an increase in fine woody debris on the ground, grass invasion is most likely to increase the amount of grass litter to the detriment of other leaf litter categories. We are unaware of studies that have explored edge influence on plant litter in savanna areas. In tropical forests, conversely, edge influence appears to be mostly driven by microclimatic changes (Magnago et al. 2015). Varying patterns of edge influence on plant litter may be observed, possibly depending on species composition and time since edge creation.

Edge characteristics are also important, as higher contrast edges, where there is a greater difference in vegetation structure between the two sides of the edges, are expected to have stronger edge influence (Cadenasso et al. 2003; Reino et al. 2009; Noreika \& Kotze 2012). However, low-contrast edges, such as narrow forest roads, may also significantly affect vegetation structure and composition by changing, for example, vegetation height and the abundance of different species (Avon et al. 2010; Dodonov et al. 2013). Edge influence on plant litter has been shown to differ between maintained and regenerating edges (Didham \& Lawton 1999) and between road and trail edges (Arévalo et al. 2008). In other studies, however, forest type (Delgado et al. 2013a) and edge development (Matlack 1993) did not influence edgerelated patterns in plant litter. Edge influence may also vary among categories of plant litter, that is woody and non-woody material or fine woody debris of different sizes. For example increases in graminoid abundance at edges are likely to increase the biomass of graminoid litter while reducing that of other litter categories, whereas an increase in woody cover would have an opposite effect. Similarly, input of plant material from outside the fragment, for example from a tree plantation, may lead to increases in fine branches or leaves but not in coarser material, which is less likely to be transported across the edge. We are, however, unaware of any studies that have explored such differences.

We studied edge influence on different categories of plant litter in fragments of Brazilian cerrado, a vegetation type encompassing both forest and savanna physiognomies, surrounded by high and low-contrast 
edges with different anthropogenic land uses. Our objectives were: (i) to quantify magnitude and distance of edge influence for different categories of plant litter, (ii) to compare edge influence among different categories of plant litter and of fine woody debris, (iii) to test whether edge and vegetation characteristics explain the variation in edge influence on fine woody debris and (iv) to qualitatively compare the patterns of edge influence observed in savanna and in forest. Due to the variation among previous studies of edge influence on plant litter, we did not make explicit predictions on the patterns that would be observed at forest edges. However, we expected that (i) there would be a marked increase in graminoid litter with concomitant decreases in other litter categories at savanna edges, (ii) edge influence would be restricted to the first 20 to $30 \mathrm{~m}$ from the edge, as has been observed for other variables in the cerrado (Dodonov et al. 2013); (iii) edge influence would be more strongly pronounced on finer portions of woody debris, as they are probably more susceptible to changes in vegetation structure and microclimate at the edges, (iv) edge influence would be stronger at higher contrast edges (Harper et al. 2005) and (v) edge influence in forest and savanna fragments would be qualitatively different, with stronger edge influence on woody debris in forest. This study complements the findings of Dodonov et al. (2013), who explored similar questions for microclimate and vegetation structure and composition in the Brazilian cerrado.

\section{METHODS}

\section{Study site}

We studied fourteen edges of eight cerrado fragments in São Paulo state with forest and savanna vegetation (Fig. 1). The study fragments were located between the coordinates $21^{\circ} 33.18^{\prime} \mathrm{S}, 47^{\circ} 36.83^{\prime} \mathrm{W}$ and $22^{\circ} 49.79^{\prime} \mathrm{S}, 50^{\circ} 22.57^{\prime} \mathrm{W}$, and were all characterized by a subtropical climate with warm rainy summers and mild dry winters. We classified one of our edges as campo cerrado, a grassland with scattered shrubs and trees (Fig. 1a); two as typical cerrado, a savanna vegetation (Fig. 1b); three as dense cerrado, a woodland with a nearly continuous canopy (Fig. 1c); and eight as cerradão, a dry forest (Fig. 1d) (Table S1) (Coutinho 1978; Ribeiro and Walter 2008). We refer to the dense cerrado and cerradão as forest sites and to the typical cerrado and campo cerrado as savanna sites. The dense cerrado and cerradão edges were characterized by an average canopy height of approximately $8-11 \mathrm{~m}$, whereas the typical cerrado and campo cerrado sites had an average canopy height of approximately 2-3.5 m (Table S1). All sites had a ground layer with a high abundance of grasses (Dodonov et al. 2013), as well as other herbaceous and woody plants including a lot of shrubs, trees and vines (P. Dodonov, pers. obs., 2010). The differences in the number of forest and savanna edges were because our study site selection was limited by the land uses adjacent to the cerrado fragments, as we wanted to sample the land uses that are most frequent next to cerrado vegetation in São Paulo state (Durigan et al. 2007). Two edges were adjacent to narrow (approximately $5 \mathrm{~m}$ wide) firebreaks with cerrado vegetation on the other side, whereas the other edges were adjacent to different anthropogenic land uses (sugar cane and eucalypt plantations, highways, and pastures) (Table S1). All edges were located at least $300 \mathrm{~m}$ (but usually more) from other edges to avoid multiple edge effects (Porensky \& Young 2013). All edges were either facing downslope (with the forest side upslope) or were on level ground and had been maintained for at least 20 years. Additional information on the study sites is available in Dodonov et al. (2013).

\section{Sampling}

We established five 180-m-long transects, going into the forest or savanna, from each study edge, except at edges F1 and F9, where we sampled only four transects. The distances between adjacent transects were determined randomly and varied between 20 and $40 \mathrm{~m}$. The first plot of each transect was located either on an embankment, which represented the edge creation line, or, in the absence of such an embankment, at a line represented by an abrupt change in the vegetation. Between November 2009 and November 2010, we collected all plant litter on the ground within $0.5 \times 0.5-\mathrm{m}$ quadrats along each transect at the following distances from the edge: $0,2,5,10,15,20,30,40$, $50,60,80,100,120,150$ and $180 \mathrm{~m}$, except for edge $\mathrm{F} 3$, where we limited the sampling to the first $100 \mathrm{~m}$ because the vegetation further from the edge had a different disturbance history. In the study areas there was a clear difference between the litter layer and the underlying soil. Although sampling took place over an extended time period, we usually took at most 3 days to sample each edge and at most two hours to sample a given transect.

We separated the litter into fine branches (diameter $\leq 1.5 \mathrm{~cm}$ ), thick branches (diameter $>1.5 \mathrm{~cm}$ ), bark and other litter. In the dense cerrado and cerradão areas we were unable to process the other litter, including leaf litter, because of time constraints. In the typical cerrado and campo cerrado areas we discarded only the parts of the litter that were too fragmented to be further classified, and separated the remaining other litter into graminoid litter and dicot leaf litter. Therefore, we had information on the biomass of twigs and bark (collectively referred to as fine woody debris - FWD) at all sites, but for graminoid and dicot leaf litter (collectively referred to as leaf litter) only at he three savanna sites, resulting in a total of three and five categories at the forest and savanna sites respectively. After sorting the litter categories, we placed them in paper bags and oven-dried them for $72 \mathrm{~h}$ at approximately $70^{\circ} \mathrm{C}$. We then used a digital scale (precision of $0.1 \mathrm{~g}$ ) to weigh the paper bags containing the litter samples and the empty litter bags, and obtained the dry weight of the litter samples by subtracting the two values. At the same spots in which we collected plant litter we also measured several other variables related to vegetation and microclimate: canopy closure, measured from hemispheric photographs with the Gap Light Analyser software (Frazer et al. 1999); maximum 
a)

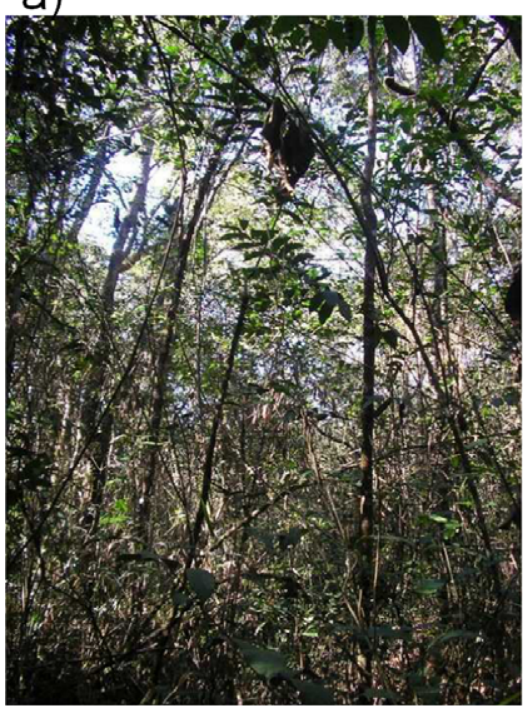

c)



b)

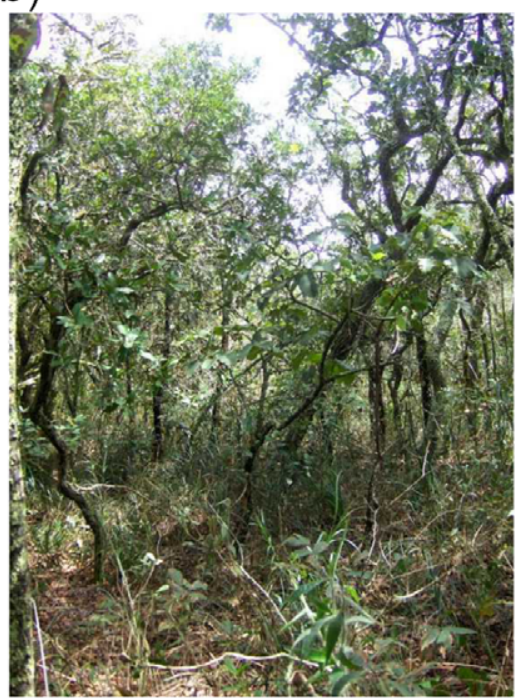

d)

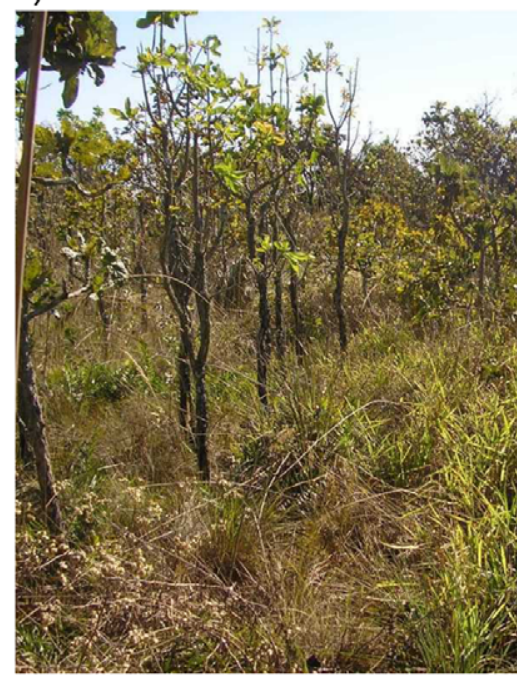

Fig. 1. Examples of the forest $(\mathrm{a}, \mathrm{b})$ and savanna (c, d) vegetation at the study edges: (a) cerradão at edge F2, (b) dense cerrado at edge $\mathrm{F} 11$, (c) typical cerrado at edge $\mathrm{S} 1$, (d) campo cerrado at edge $\mathrm{S} 3$.

vegetation height, measured with an expandable $15-\mathrm{m}$ ruler; air temperature and moisture; and the biomass of invasive and native graminoids. Edge influence on these variables has been explored by Dodonov et al. (2013).

\section{Data analysis}

We estimated magnitude, significance and distance of edge influence by comparing values at each distance from the edge with reference conditions. We considered samples collected at 120, 150 and $180 \mathrm{~m}$ from the edge as representative of interior conditions and used them as reference values, except for edge F3, where we used samples collected at 80 and $100 \mathrm{~m}$ as reference. We first calculated the magnitude of edge influence as $(E-I) /(E+I)$, where $E$ is the mean value at a given distance from the edge and $I$ the mean of interior values (Harper et al. 2005). We used a randomization procedure (randomization test for assessing edge influence - Harper \& Macdonald 2011) to assess whether this magnitude was significantly different from zero at each distance from the edge. This analysis proceeds as follows:

1. calculate the magnitude of edge influence using the values at a distance from the edge and the reference values;

2. create a data set containing both the edge values and the reference values;

3. randomly assign five of these values as edge and the remaining as reference;

4. recalculate magnitude of edge influence for the randomized data set and repeat steps $2-4$."

The magnitude of edge influence values from 9999 randomizations plus the observed value were then used to calculate the significance of the difference between edge and interior values for each distance. We considered distances 
with a $P$-value of 0.05 or lower as significantly different from reference conditions.

We considered edge influence to be significant (i.e. significance of edge influence $=1$ ) when at least one distance within the first $15 \mathrm{~m}$ from the edge was significantly different from reference conditions, and estimated distance of edge influence as the set of distances that were significantly different from reference conditions interrupted by no more than one non-significant distance. At the edges with significant edge influence we estimated the magnitude of edge influence as the maximum absolute value that was significantly different from reference conditions. At the other edges we recalculated the magnitude of edge influence by comparing the mean values at the first $15 \mathrm{~m}$ from the edge to the reference conditions.

We tested whether the magnitude of edge influence differed among the FWD categories (fine branches, thick branches, bark, and total amount of FWD) by means of Friedman's test followed by pairwise Wilcoxon tests. We did not assess differences in the significance or distance of edge influence because of the low number of edges with significant edge influence for some categories, and we did not include leaf litter because we had data for only three edges.

We also tested whether vegetation and edge characteristics explain the variation in the significance and magnitude of edge influence by means of a model selection with generalized linear models with a binomial distribution for significance and a normal distribution for magnitude of edge influence. We used three explanatory variables: canopy closure, edge contrast, and edge exposure. For canopy closure, we used the mean values measured between 0 and $20 \mathrm{~m}$ from the edge. For edge contrast, we used the weighted edge contrast measure (Dodonov et al. 2013), which considers the difference in height between the fragment (measured as the average height between 0 and $20 \mathrm{~m}$ from the edge) and the surrounding land uses at different distances into the matrix, giving more emphasis to land uses closer to the edge. This measure is calculated by (i) calculating the contrast with the land use at all distances from the edge (in our case between 0 and $40 \mathrm{~m}$ ), (ii) multiplying these contrasts by a weighting function (we used a half-normal with a mean of 0 and a standard deviation of $5 \mathrm{~m}$ ) and (iii) calculating the area below the resulting curve (Dodonov et al. 2013). Edge exposure is the distance to the nearest land use as tall or taller than the fragment's vegetation, up to a maximum of $50 \mathrm{~m}$.

For each FWD category, we compared six models: three models with one explanatory variable each, two models combining canopy closure with each of the other explanatory variables, and a null model. We compared them with Akaike's information criterion corrected for small sample size (AICc). We considered a model to be significantly better than the other when its AIC was at least two units lower than the next best model; when two or more models had similar AIC values $(\triangle \mathrm{AICc}<2)$, we chose the models with fewer variables. We restricted these analyses to the forest edges to avoid the confounding effects of differences in vegetation structure, as our number of savanna edges was too small for a two-way analysis. We did not analyse the distance of edge influence because of the low number of edges with significant edge influence, and we did not perform this analysis on the significance of edge influence for thick twigs because it was significant at a single edge.

We performed the randomization tests and the model selection in R 2.15.3 (R Core Team 2013) and the Friedman and Wilcoxon tests in Past 2.17c (Hammer et al. 2001). The codes used for the randomization tests and calculation of weighted edge contrast are available in Dodonov et al. (2013) and at https://github.com/pdodonov/EdgeInfluence.

\section{RESULTS}

Edge influence was significant at two or more edges for all response variables except for thick twigs and total leaf litter, which were significantly different from references conditions at only one edge each (Fig. 2,



Fig. 2. Variation in magnitude of edge influence (MEI; varying from -1 to +1 ) for different categories of fine woody debris (FWD) and leaf litter. Each point is a study edge, with triangles representing savanna edges and circles representing forest edges. Filled symbols represent edges for which a significant edge influence was detected. Magnitude of edge influence for bark was significantly greater $(P=0.001$, Wilcoxon test) than that for fine twigs and for total FWD. 
Table 1). All three savanna edges and seven of the eleven forest edges had significant edge influence for at least one FWD category. At the edges with significant edge influence, the biomass was smaller for fine twigs and dicot leaf litter and greater for graminoid litter at the edge compared with reference conditions, whereas bark and total FWD variables showed variable patterns regardless of vegetation type. At these edges, magnitude of edge influence was most variable for bark and least variable for fine twigs and for graminoid litter.

Distance of edge influence usually ranged between 0 and $20 \mathrm{~m}$, although values of 40 and $50 \mathrm{~m}$ were also observed (Table 1, Figs 3,4). There was great variation in distance of edge influence for all FWD categories except thick twigs and total leaf litter, from 0 to 40 or $50 \mathrm{~m}$ for fine twigs, bark, total FWD, and dicot leaf litter, which was only sampled at three edges. Edge influence on graminoid litter was more consistent and only extended from 0 to $5 \mathrm{~m}$.

The magnitude of edge influence for thick twigs was greater than for fine twigs or for total FWD (Friedman test, $P=0.02$; pairwise Wilcoxon tests, $P=0.01$; Fig. 2). When assessing the effects of edge characteristics on magnitude of edge influence and the number of edges with significant edge influence, the null model was always the best model $(\triangle \mathrm{AICc}=0)$, except for significance of edge influence on total FWD, for which the best model included canopy cover but the null model was also plausible $(\triangle \mathrm{AICc}=1.4$, Table 2$)$. There were no clear differences between edges adjacent to different land uses (Table 1).

\section{DISCUSSION}

Even though we observed large differences in the magnitude of edge influence on plant litter among our cerrado edges, the distance of edge influence had reasonably consistent values of around $20 \mathrm{~m}$, which agrees with estimates for other vegetation characteristics, including canopy closure, vegetation height and the abundance of native and invasive graminoids, at the same study sites (Dodonov et al. 2013). It therefore appears that, agreeing with our expectations, most edge-related ecological changes in cerrado vegetation occur within $20 \mathrm{~m}$ of the edge. To our knowledge, these are among the first estimates of distance of edge influence for the litter or other variables in the cerrado and for plant litter in general (but see Matlack 1993; Didham 1998; Delgado et al. 2013a, b; Dodonov et al. 2013). We also detected differences in the patterns observed for different parts of the plant litter, which, to our knowledge, had not been explored in previous studies.

The large variation in the observed patterns has been previously found in other studies relating plant litter to edges (Didham \& Lawton 1999; Portela \& Santos 2007; Delgado et al. 2013a,b). However, we also noticed that different portions of plant litter were affected by edges in different ways, which suggests

Table 1. Set of distances (m) that were significant from reference conditions for the biomass of fine woody debris (FWD) and leaf litter at the savanna and forest study sites

\begin{tabular}{|c|c|c|c|c|c|c|c|c|}
\hline Edge & $\begin{array}{l}\text { Main adjacent } \\
\text { land use }\end{array}$ & Fine twigs & $\begin{array}{l}\text { Thick } \\
\text { twigs }\end{array}$ & Bark & Total FWD & $\begin{array}{c}\text { Graminoid } \\
\text { litter }\end{array}$ & Dicot leaf litter & $\begin{array}{c}\text { Total leaf } \\
\text { litter }\end{array}$ \\
\hline \multicolumn{9}{|c|}{ Savanna } \\
\hline S1 & Pasture & $\underline{O}$ & ns & ns & $\underline{0}$ & 5 & $\underline{0}$ & $\underline{0}$ \\
\hline $\mathrm{S} 2$ & Urban & $\overline{2} 0$ & ns & $10,15,40$ & $\overline{5}, 10,20,80$ & $\underline{0}$ & $\overline{\mathrm{ns}}$ & $\overline{\mathrm{n}} \mathrm{s}$ \\
\hline S3 & Eucalyptus & 5,40 & ns & $\overline{n s}$ & 5,40 & $\overline{2}, 5,40$ & $0-5,15,20,40$ & ns \\
\hline \multicolumn{9}{|l|}{ Forest } \\
\hline F1 & Firebreak & ns & ns & ns & ns & $\mathrm{N} / \mathrm{A}$ & $\mathrm{N} / \mathrm{A}$ & $\mathrm{N} / \mathrm{A}$ \\
\hline $\mathrm{F} 2$ & Firebreak & $\underline{5}$ & ns & 30 & ns & $\mathrm{N} / \mathrm{A}$ & $\mathrm{N} / \mathrm{A}$ & N/A \\
\hline F3 & Highway & $\overline{10}, 20,40-50$ & ns & $\underline{10}$ & $10,20,50$ & N/A & N/A & $\mathrm{N} / \mathrm{A}$ \\
\hline $\mathrm{F} 4$ & Pasture & $\overline{20}$ & ns & $\overline{\mathrm{ns}}$ & $\overline{10,20}$ & $\mathrm{~N} / \mathrm{A}$ & $\mathrm{N} / \mathrm{A}$ & $\mathrm{N} / \mathrm{A}$ \\
\hline F5 & Pasture & ns & ns & ns & $\overline{\mathrm{ns}}$ & $\mathrm{N} / \mathrm{A}$ & $\mathrm{N} / \mathrm{A}$ & $\mathrm{N} / \mathrm{A}$ \\
\hline F6 & Highway & ns & ns & 2 & ns & $\mathrm{N} / \mathrm{A}$ & $\mathrm{N} / \mathrm{A}$ & $\mathrm{N} / \mathrm{A}$ \\
\hline F7 & Highway & $\underline{0,} 100$ & 100 & $\overline{\mathrm{n}} \mathrm{s}$ & ns & $\mathrm{N} / \mathrm{A}$ & $\mathrm{N} / \mathrm{A}$ & $\mathrm{N} / \mathrm{A}$ \\
\hline F8 & Sugarcane & $\overline{\mathrm{ns}}$ & 5 & 80 & 5,80 & N/A & N/A & N/A \\
\hline F9 & Sugarcane & ns & $\overline{\mathrm{n}} \mathrm{s}$ & 20 & ns & N/A & N/A & N/A \\
\hline F10 & Eucalyptus & 60 & ns & 50 & $\underline{0}$ & $\mathrm{~N} / \mathrm{A}$ & N/A & $\mathrm{N} / \mathrm{A}$ \\
\hline F11 & Eucalyptus & ns & ns & ns & $\overline{\mathrm{ns}}$ & N/A & N/A & N/A \\
\hline
\end{tabular}

N/A, this variable was not measured at this edge; ns, no significant edge influence was observed at this edge. Results for FWD are divided into fine and thick twigs ( $<$ and $>1.5 \mathrm{~cm}$ in diameter respectively), bark, and total FWD; results for leaf litter are divided into dicot leaf litter, grasses and total leaf litter. Distances considered to represent edge influence are underlined. Distances with values lower than in the interior (negative edge influence) are in italics. 
a) S1 - Fine twigs



e) F7 - Fine twigs

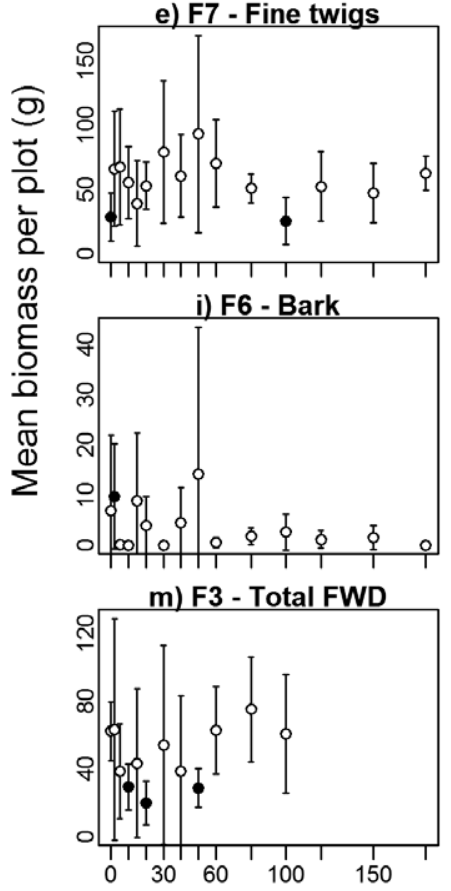

b) 53 - Fine twigs

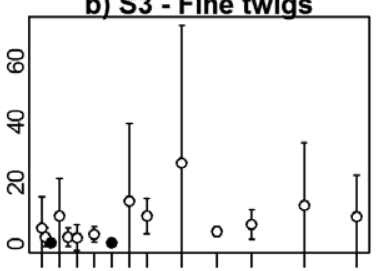

f) F8 - Thick twigs
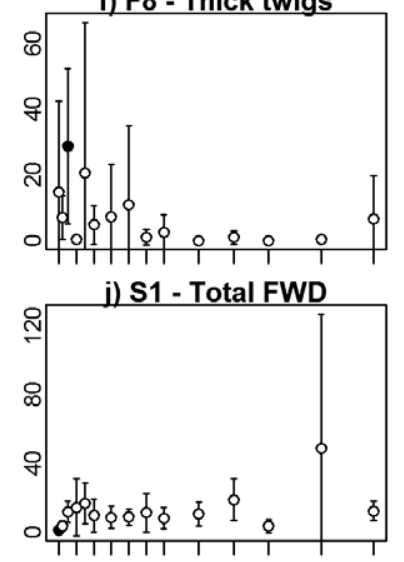

n) F4 - Total FWD

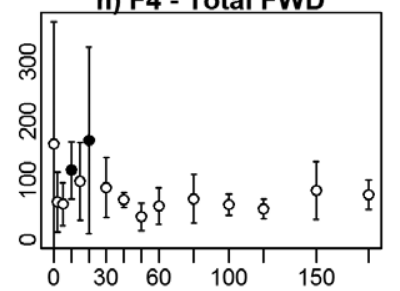

c) F2 - Fine twigs



g) 52 - Bark

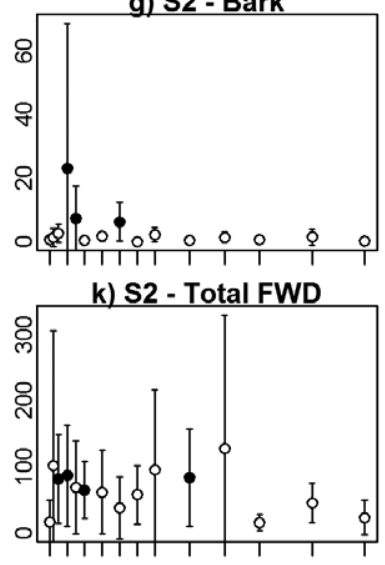

o) F8 - Total FWD

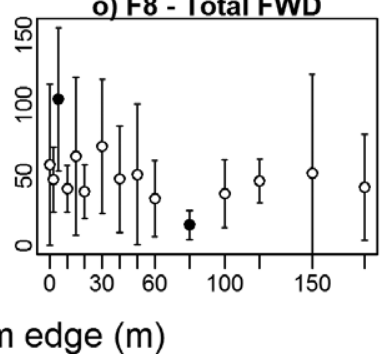

d) F3 - Fine twigs

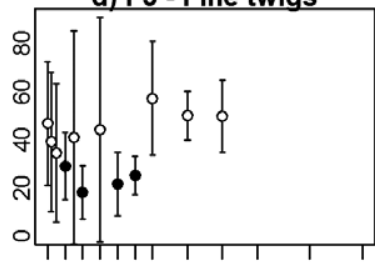

h) F3 - Bark



p) F10 - Total FWD

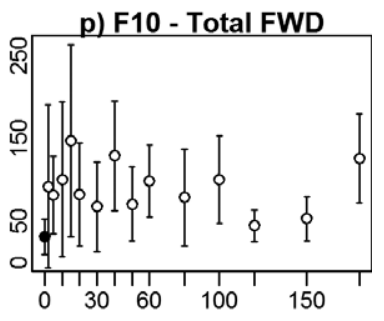

Distance from edge $(\mathrm{m})$

Fig. 3. Variation in fine woody debris (FWD) biomass with distance from edge for the edges with significant edge influence. Filled symbols were significantly different from reference values (80-100 m at edge F3 and 120-180 m at the other edges).

that an assessment of total plant litter biomass may hide underlying patterns. For example as expected, edge influence was more pronounced on fine twigs than on thick twigs or bark. Edge influence on fine twigs tended to be negative, whereas thick twigs were little affected by edges. Edge influence at savanna sites also agreed with our expectations, as the biomass of graminoid litter increased at the edges, whereas that of dicot leaf litter decreased. The greater magnitude of edge influence observed for thick twigs than for fine twigs provides further support for different effects of edges on different components of litter.

The lower amount of fine twigs at edges may appear counter-intuitive, as increased wind incidence, which is common at tropical forest edges (Laurance \& Curran 2008), would result in the opposite pattern. We propose two mechanisms to explain the observed pattern. First, species composition may be different between edge and interior of cerrado fragments (Jardim \& Batalha 2009), and decreased FWD production would be expected if the species at the edge had a reduced tendency to lose small branches. Second, intra-specific variation in plant growth and architecture has been previously related to edges (Lima-Ribeiro 2008; Habermann \& Bressan 2011) and to other disturbances (Dodonov et al. 2011, 2014) in the cerrado. It is thus possible that species growing at cerrado edges have a different architecture, with a smaller propensity for twig breakage, than those growing in the interior. An overall decrease in primary productivity at the edges would also explain the observed pattern, but this is not likely in our study site as the woody vegetation is often taller and denser at cerrado edges compared to interior areas (Lima-Ribeiro 2008; Dodonov et al. 2013; Mendonça et al. 2015).

Agreeing with our expectations, other FWD categories were either not influenced by edges, as for thick twigs, or had no consistent patterns. This probably reflects the large spatial and temporal variation in these variables and their dependency on other 
a) S1 - Graminoid litter

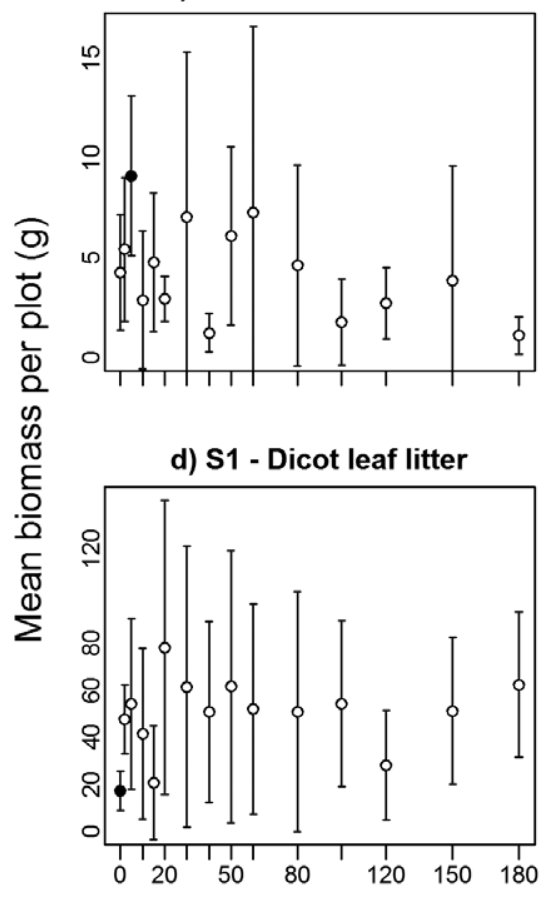

b) S2 - Graminoid litter

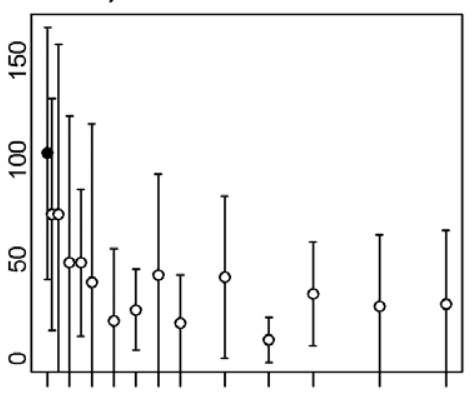

e) S3 - Dicot leaf litter

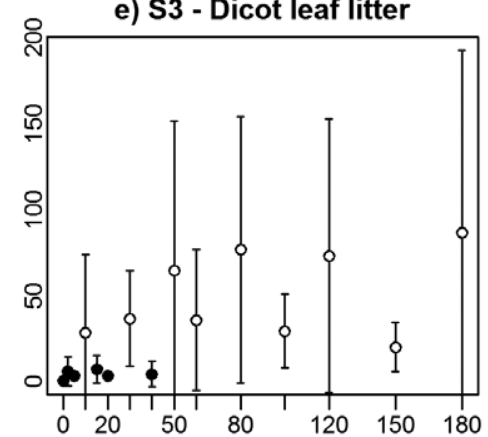

c) S3 - Graminoid litter
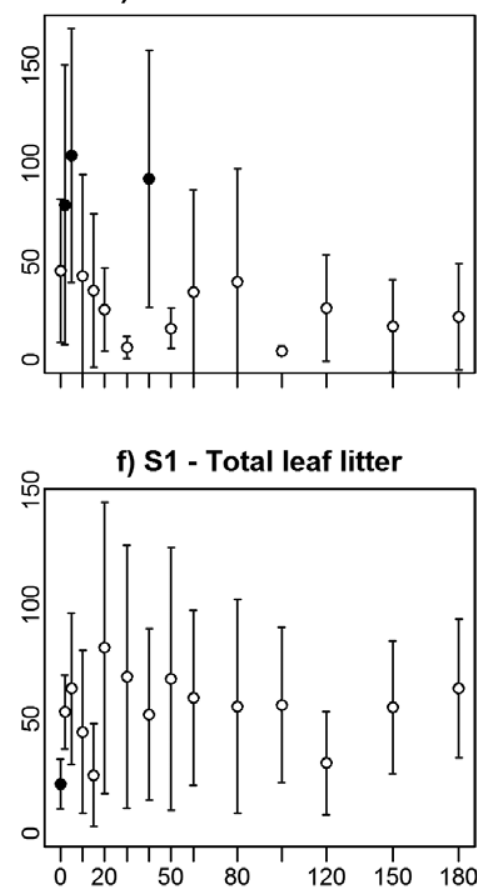

Distance from edge $(\mathrm{m})$

Fig. 4. Variation in leaf litter biomass with distance from edge for the savanna edges with significant edge influence. Filled symbols were significantly different from reference values $(120-180 \mathrm{~m})$.

Table 2. Model selection relating edge influence on different categories of fine woody debris (FWD) with different edge characteristics, performed for our 11 forest edges

Explanatory variables in the model

\begin{tabular}{llllllll}
$\begin{array}{l}\text { Edge influence } \\
\text { parameter }\end{array}$ & Response variable & Null & Closure & Contrast & Exposure & $\begin{array}{c}\text { Closure, } \\
\text { contrast }\end{array}$ & $\begin{array}{c}\text { Closure, } \\
\text { exposure }\end{array}$ \\
\hline Significance & Fine twigs & 0 & 2.8 & 0.8 & 2.9 & 4.7 & 6.6 \\
& Bark & 0 & 3 & 2.7 & 3 & 6.6 & 6.9 \\
Magnitude & Total FWD & 1.4 & 0 & 3.5 & 4.3 & 2.7 & 3 \\
& Fine twigs & 0 & 3.9 & 3.6 & 3.3 & 8.8 & 8.5 \\
& Thick twigs & 0 & 2.8 & 3.7 & 1.4 & 7.8 & 5.8 \\
& Bark & 0 & 1.9 & 2.9 & 2.5 & 6.2 & 6 \\
& Total FWD & 0 & 3.5 & 3.6 & 1.5 & 8.5 & 6.6 \\
\hline
\end{tabular}

Each model is represented by its $\triangle \mathrm{AICc}$, or the difference in Akaike's information criterion between a given model and the best model for this response variable. Results are divided into fine and thick twigs ( $<$ and $>1.5 \mathrm{~cm}$ in diameter respectively), bark, and total FWD. Edge influence was characterized by its significance (a binary variable representing whether edge influence was significant at a given edge) and magnitude (calculated as $(E-I) /(E+I)$, where $E$ is the average biomass at the edge and $I$ is the average biomass in reference conditions). Significance of edge influence on thick twigs was not assessed because it was significant at a single edge.

vegetation characteristics. The amount of bark would depend mostly on the species present, as there is a lot of variation in bark thickness among cerrado plants (Hoffman et al. 2003). Similarly, the loss of thick twigs may be related to gap formation, which is highly heterogeneous in both space and time. As expected, graminoid biomass was consistently greater at savanna edges. Dodonov et al. (2013) observed increased biomass of the African grass Urochloa decumbens close to the edge at the three savanna sites studied here (distance of edge influence of $0-15 \mathrm{~m}$ ) and a concomitant decrease in the biomass of native 
graminoids (distance of edge influence of 5-10 m) at two of the three sites, but no edge influence on another other dominant African grass, Melinis minutiflora. As the total biomass of native graminoids at these sites was smaller than that of $U$. decumbens (Dodonov et al. 2013), an increase in the abundance of this species at the edge is probably the main cause of the increase in graminoid litter. Considering that invasion by this species is common at cerrado edges (Pivello et al. 1999a,b; Mendonça et al. 2015) and that African grasses tend to have greater aboveground biomass than Neotropical grasses (Williams \& Baruch 2000), an increase in graminoid litter is likely to be common at cerrado edges in general. African grasses may also negatively affect native woody species (Hoffman \& Haridasan 2008), and their increased abundance at edges may thus explain the lower amount of dicot leaf litter and possibly contribute to edge influence on FWD.

Contrary to our expectations, we did not observe conspicuous differences in edge influence on FWD between forest and savanna vegetation. Thus, the biomass of fine twigs was lower at the edge than in the interior and variable patterns were observed for bark and total FWD regardless of vegetation type. This may be related to the floristic similarity among the vegetation types comprising the cerrado vegetation. Although there are considerable differences in vegetation structure among the different phytophysiognomies (Batalha et al. 2001), floristic differences are often much smaller, with the same species occurring in both forest and savanna vegetation (Batalha \& Mantovani 2001; Pinheiro \& Durigan 2012). As the same species occur in both savanna and forest vegetation, they are likely to be adapted to the microclimatic conditions characteristic of open vegetation and of forest edges, and thus likely to be less affected by edge influence than forest specialist species. This, however, does not discard the possibility that the mechanisms of edge influence may vary between forest and savanna vegetation; different mechanisms, for example microclimatic stress and grass invasion, may putatively lead to the same patterns.

Edge characteristics do not appear to explain the variation in either magnitude of edge influence or significance of edge influence. Therefore, it appears that both high- and low-contrast edges may significantly alter plant litter biomass and other ecological characteristics. This was unexpected, as edge contrast and land use often affect the patterns and intensity of edge influence (Wright et al. 2012; Aragon et al. 2015). However, similar results of no effects of edge contrast on edge influence have been previously found for air temperature, canopy cover and vegetation height in the cerrado (Dodonov et al. 2013). The large time span over which sampling was performed may have also added to the variation among edges, hampering the detection of a relation with edge contrast, as there is seasonal variation in litterfall in the cerrado (Valenti et al. 2008). However, this seasonal variation is likely to be the same between edge and interior areas, as we know of no evidence of an increase in the abundance of deciduous species at cerrado edges. The apparent lack of effect of edge contrast may also be due to the limited variation in the land uses immediately adjacent to the edges. All of our edges were adjacent either to firebreaks with no vegetation or to grass-dominated areas, which separated the cerrado fragment from the other land uses. It is thus possible that the immediate edge exerts at least as much influence as the nearby dominant land use in the matrix, precluding the detection of differences in edge influence between edge types. For example, eucalypt edges could putatively contribute FWD and leaf litter to the cerrado, increasing litter biomass at the edge. However, the existence of a firebreak between the plantation and the cerrado may preclude this from happening as most of the fallen litter would remain in the firebreak and not reach the cerrado. Similarly, firebreaks may increase the similarity in microclimatic conditions among edges, leading to smaller land use effects than would be observed if there were no separation between the cerrado and the dominant land use (Wright et al. 2012).

In conclusion, notwithstanding the large variation in edge influence on plant litter in the cerrado, smaller portions of FWD tend to have lower biomass near edges whereas dead graminoid biomass tends to be greater. Considering that graminoid biomass is much more representative in savanna areas and the biomass of FWD is more abundant in forests, edgerelated variation in plant litter may have different ecological consequences in these environments. Thus, the increased amount of graminoid leaf litter at savanna edges is likely to increase fire frequency at these edges due to increased fuel availability (Hoffmann et al. 2012), but the same would not necessarily be observed in forests, especially considering that exotic graminoids are often restricted to the immediate edge of dense cerrado and cerradão areas (Dodonov et al. 2013). The smaller amount of fine twigs and, in some cases, other FWD categories at the edges may also have ecological consequences for litter invertebrates, as a decrease in the amount of litter may lead to decreased invertebrate abundance (Delgado et al. 2013b), with possible cascading effects into higher trophic levels by, for example decreasing food availability for insectivorous ground vertebrates. Future studies could explore the mechanisms of edge influence on plant litter in the cerrado and other savanna and forest ecosystems, as well as their consequences for different organisms and ecological processes. 


\section{ACKNOWLEDGEMENTS}

We thank the many people who helped us in the field, especially Everton Recco and Rafael Xavier; the Forestry Institute of São Paulo State, the Botanical Garden of Bauru, Embrapa Southeast Livestock and the owner of Farm América for permissions and logistic support; the Department of Botany of the Federal University of São Carlos for storage space for the litter samples during processing. PD was funded by the São Paulo State Research Foundation (FAPESP) (MSc Grant 2008/07772-0), the National Counsel of Technological and Scientific Development (CNPq) (PhD grant 141623/2011-0) and the Coordination for the Improvement of Higher Education Personnel (CAPES - PNPD program). ALB was partially funded by the Tutorial Education Program (PET) of the Brazilian Ministry of Education.

\section{REFERENCES}

Aragon G., Abuja L., Belinchón R. \& Martínez I. (2015) Edge type determines the intensity of forest edge effects on epiphytic communities. Eur. F. For. Res. 134, 443-51.

Arévalo J. R., Delgado J. D. \& Fernández-Palacions J. M. (2008) Changes in plant species composition and litter production in response to roads and trails in the laurel forest of Tenerife (Canary Islands). Plant Biosyst. 142, 614-22.

Avon C., Bergès L., Dumas Y. \& Dupouey J. L. (2010) Does the effect of forest roads extend a few meters or more into the adjacent forest? A study on understory plant diversity in managed oak stands. For. Ecol. Manage. 259, 1546-55.

Batalha M. A. \& Mantovani W. (2001) Floristic composition of the cerrado in the Pé-de-Gigante reserve (Santa Rita do Passa Quatro, Southeaster Brazil). Acta Bot. Bras. 15, 289 304.

Batalha M. A., Mantovani W. \& Mesquita Júnior H. N. (2001) Vegetation structure in cerrado physiognomies in SouthEastern Brazil. Braz. F. Biol. 61, 475-83.

Bettez N. D., Marino R., Howarth R. W. \& Davidson E. A. (2013) Roads as nitrogen deposition hot spots. Biogeochemistry 114, 149-63.

Bowering M., LeMay V. \& Marshall P. (2006) Effects of forest roads on the growth of adjacent lodgepole pine trees. Can. F. For. Res. 36, 919-29.

Cadenasso M. L., Pickett S. T. A., Weathers K. C. \& Jones C. G. (2003) A framework for a theory of ecological boundaries. Bioscience 53, 750-8.

Christianini V. L. \& Oliveira P. S. (2013) Edge effects decrease ant-derived benefits to seedlings in a neotropical savanna Arthropod-Plant Interact. 7, 191-9.

Cilliers S. S., Williams N. S. G. \& Barnard F. J. (2008) Patterns of exotic plant invasions in fragmented urban and rural grasslands across continents. Landsc. Ecol. 23, 1243 56.

Coutinho L. M. (1978) O conceito de cerrado. Rev. Bras. Bot., 1, 17-23.

Delgado J. N., Arroyo N. L., Arevalo J. R. \& FernandezPalacios J. M. (2007) Edge effects of roads on temperature, light, canopy closure, and canopy height in laurel and pine forests (Tenerife, Canary Islands). Landsc. Urban Plan. 81, 328-40.

Delgado J. D., Arroyo N. L., Arévalo J. R. \& FernándezPalacios J. M. (2013a) Road edge effects on litter invertebrate communities of subtropical forests. F. Nat. Hist. 47, 203-36.

Delgado J. D., Morales G. M., Arroyo N. L. \& FernándezPalacios J. M. (2013b) The responses of leaf litter invertebrates to environmental gradients along road edges in subtropical island forests. Pedobiologia 56, 137-46.

Didham R. K. (1998) Altered leaf-litter decomposition rates in tropical forest fragments. Oecologia 116, 397-406.

Didham R. K. \& Lawton J. H. (1999) Edge structure determines the magnitude of changes in microclimate and vegetation structure in tropical forest fragments. Biotropica 31, 17-30.

Dodonov P., Lucena I. C., Leite M. B. \& Silva-Matos D. M. (2011) Allometry of some woody plant species in a Brazilian savanna after two years of a dry season fire. Braz. 7. Biol. 71, 527-35.

Dodonov P., Harper K. A. \& Silva-Matos D. M. (2013) The role of edge contrast and forest structure in edge influence: vegetation and microclimate at edges in the Brazilian cerrado. Plant Ecol. 214, 1345-59.

Dodonov P., Xavier R. O., Tiberio F. C., Lucena I. C., Zanelli C. B. \& Silva-Matos D. M. (2014) Driving factors of small-scale variability in a savanna plant population after a fire. Acta Oecol. 56, 47-55.

Durigan G., Siqueira M. F. \& Franco G. A. D. C. (2007) Threats to the cerrado remnants of the State of São Paulo, Brazil. Sci. Agric. 64, 355-63.

Fahrig L. (2003) Effects of habitat fragmentation on biodiversity. Annu. Rev. Ecol. Evol. Syst. 34, 487-515.

Frazer G. W., Canham C. D. \& Lertzman K. P. (1999) Gap Light Analyzer (GLA): Imaging Software to Extract Canopy Structure and Light Transmission Indices from True-Colour Fisheye Photographs, Users Manual and Program Documentation. Simon Fraser University, Burnaby, British Columbia.

Habermann G. \& Bressan A. C. (2011) Root, shoot and leaf traits of the congeneric Styrax species may explain their distribution patterns in the cerrado sensu lato areas in Brazil. Funct. Plant Ecol. 38, 209-18.

Hammer Ø., Harper D. A. T. \& Ryan P. D. (2001) PAST: paleontological statistics soft-ware package for education, and data analysis. Palaeontol. Electron. 4, 9. [Cited 5 August 2016.] Available from URL: http://palaeo-electronica. org/2001_1/past/issue1_01.htm.

Harper K. A. \& Macdonald S. E. (2011) Quantifying distance of edge influence: a comparison of methods and a new randomization method. Ecosphere 2, art94.

Harper K. A., Macdonald S. E., Burton P. K. et al. (2005) Edge influence on forest structure and composition in fragmented landscapes. Conserv. Biol. 19, 768-82.

Haskell D. G. (2000) Effects of forest roads on macroinvertebrate soil fauna of the southern Appalachian mountains. Conserv. Biol. 14, 57-63.

Hoffman W. A. \& Haridasan M. (2008) The invasive grass, Melinis minutiflora, inhibits tree regeneration in a Neotropical savanna. Austral Ecol. 33, 29-36.

Hoffman W. A., Orthen B. \& Nascimento P. K. (2003) Comparative fire ecology of tropical savanna and forest trees. Funct. Ecol. 17, 720-6.

Hoffmann W. A., Jaconis S. Y., McKinley K. L., Geiger E. L., Gotsch S. G. \& Franco A. C. (2012) Fuels or microclimate? Understanding the drivers of fire feedbacks at savanna-forest boundaries. Austral Ecol. 37, 634-43. 
Huang B. Q., Sun Y. N., Yu X. H., Luo Y. B., Hutchings M. J. \& Tang S. Y. (2009) Impacts of proximity to a pathway on orchid pollination success in Huanglong National Park, south-west China. Biol. Conserv. 142, 701-8.

Jardim A. V. F. \& Batalha M. (2009) Dispersal syndromes related to edge distance in cerrado sensu stricto fragments of centralwestern Brazil. Braz. Arch. Biol. Technol. 52, 1167-77.

Laurance W. F. \& Curran T. J. (2008) Impacts of wind disturbance on fragmented tropical forests: a review and synthesis. Austral Ecol. 33, 399-408.

Lima-Ribeiro M. D. (2008) Edge effects on vegetation and population structure in Cerradão fragments of Southwest Goiás, Brazil. Acta Bot. Bras. 22, 535-45.

Loydi A., Lohse K., Otte A., Donath T. W. \& Eckstein R. L. (2014) Distribution and effects of tree leaf liter on vegetation composition and biomass in a forest-grassland ecotone. F. Plant Ecol. 7, 264-75.

Magnago L. F. S., Rocha M. F., Meyer L., Martins S. V. \& Meira-Neto J. A. A. (2015) Microclimatic conditions at forest edges have significant impacts on vegetation structure in large Atlantic forest fragments. Biodivers. Conserv. 24, 2305-18.

Magrach A., Rodríguez-Pérez J., Campbell M. \& Laurance W. F. (2014) Edge effects shape the spatial distribution of lianas and epiphytic ferns in Australian tropical rain forest fragments. Appl. Veg. Sci. 17, 754-64.

Matlack G. R. (1993) Microenvironment variation within and among forest edge sites in the eastern United States. Biol. Conserv. 66, 185-94.

Mendonça A. H., Russo C., Melo A. C. \& Durigan G. (2015) Edge effects in savanna fragments: a case study in the cerrado. Plant Ecol. Divers 8, 493-503.

Moreno M. L., Bernaschini M. L., Pérez-Harguindeguy N. \& Valladares G. (2014) Area and edge effects on leaf-litter decomposition in a fragmented subtropical dry forest. Acta Oecol. 60, 26-9.

Noreika N. \& Kotze D. J. (2012) Forest edge contrasts have a predictable effect on the spatial distribution of carabid beetles in urban forests. F. Insect Conserv. 16, 867-81.

Pinheiro E. S. \& Durigan G. (2012) Diferenças florísticas e estruturais entre fitofisionomias no cerrado em Assis, SP, Brasil. Revista Árvore 8, 181-93.

Pivello V. R., Carvalho V. M. C., Lopes P. F., Peccinini A. A. \& Rosso S. (1999a) Abundance and distribution of native and alien grasses in a "cerrado" (Brazilian savanna) biological reserve. Biotropica 31, 71-82.

Pivello V. R., Shida C. N. \& Meirelles S. T. (1999b) Alien grasses in Brazilian savannas: a threat to the biodiversity. Biodivers. Conserv. 8, 1281-94.

Pohlman C. L., Turton S. M. \& Goosem M. (2007) Edge effects of linear canopy openings on tropical rain forest understory microclimate. Biotropica 39, 62-71.

Porensky L. M. \& Young T. P. (2013) Edge-effect interactions in fragmented and patchy landscapes. Conserv. Biol. 27, 509-19.

Portela R. C. \& Santos F. A. (2007) Produção e espessura da serapilheira na borda e interior de fragmentos florestais de mata atlântica de diferentes tamanhos. Rev. Bras. Bot. 30, 271-80.

$\mathrm{R}$ Core Team (2013) R: A Language and Environment for Statistical Computing. $\mathrm{R}$ Foundation for Statistical Computing, Vienna, Austria. [Cited 3 January 2013.] Available from URL: http://www.R-project.org/.
Reino L., Beja P., Osborne P. E., Morgado R., Fabião A. \& Rotenberry J. T. (2009) Distance to edges, edge contrast and landscape fragmentation: interactions affecting farmland birds around forest plantations. Biol. Conserv. $142,824-38$

Ribeiro J. F. \& Walter B. M. T. (2008) As principais fisionomias do bioma Cerrado. In: Cerrado: Ecologia e Flora (eds S. M. Sano, S. P. Almeida \& J. F. Ribeiro) pp. 15199. Embrapa Informação Tecnológicas, Brasília.

Riutta T., Slade E. M., Bebber D. P. et al. (2012) Experimental evidence for the interacting effects of forest edge, moisture and soil macrofauna on leaf litter decomposition. Soil Biol. Biogeochem. 49, 124-31.

Rubinstein A. \& Vasconcelos H. L. (2005) Leaf-litter decomposition in Amazonian forest fragments. F. Trop. Ecol. 21, 699-702.

Sayer E. J. (2006) Using experimental manipulation to assess the roles of leaf litter in the functioning of forest ecosystems. Biol. Rev. 81, 1-31.

Sizer N. C., Tanner E. V. \& Ferraz I. D. (2000) Edge effects on litterfall mass and nutrient concentrations in forest fragments in central Amazonia. F. Trop. Ecol. 16, 853-63.

Smit I. P. J. \& Asner G. P. (2012) Roads increase woody cover under varying geological, rainfall and fire regimes in African savanna. F. Arid Environ. 80, 74-80.

Taboada A., Kotze D. J. \& Salgado J. M. (2004) Carabid beetle occurrence at the edges of oak and beech forests in NW Spain. Eur. F. Entomol. 101, 555-63.

Valenti M. W., Cianciaruso M. V. \& Batalha M. A. (2008) Seasonality in litterfall and leaf decomposition in a cerrado site. Braz. F. Biol. 68, 459-65.

Valladares G., Salvo A. \& Cagnolo L. (2006) Habitat fragmentation effects on trophic processes of insect-plant food webs. Conserv. Biol. 20, 212-7.

Vasconcelos H. L. \& Luizão F. J. (2004) Litter production and litter nutrient concentrations in a fragmented Amazonian landscape. Ecol. Appl. 14, 884-92.

Vidal M. M., Pivello V. R., Meirelles S. T. \& Metzger J. P. (2007) Produção de serapilheira em floresta atlântica secundária numa paisagem fragmentada (Ibiúna, SP): importância da borda e tamanho dos fragmentos. Rev. Bras. Bot. 30, 521-32.

Williams D. G. \& Baruch Z. (2000) African grass invasion in the Americas: ecosystem consequences and the role of ecophysiology. Biol. Invas. 2, 123-40.

Wright T. E., Tausz M., Kasel S., Volkova L., Merchant A. \& Bennet L. T. (2012) Edge type affects leaf-level water relations and estimated transpiration of Eucalyptus arenacea. Tree Physiol. 32, 280-93.

\section{SUPPORTING INFORMATION}

Additional Supporting Information may be found in the online version of this article at the publisher's web-site:

Table S1. Edge designation, location, geographical coordinates and edge characteristics of the 14 edges sampled in this study. 